\title{
Determinants of Diarrheal Diseases among Under Five Children in Jimma Geneti District, Oromia Region, Ethiopia, 2020: a case-control study
}

\section{Dejene Mosisa}

Ambo University

Mecha Aboma ( $\square$ abomamecha@gmail.com )

Ambo University

Teka Girma

Ambo University

Abera Shibru

Ambo University

\section{Research Article}

Keywords: Unmatched, Case-Control, Determinants, Diarrhea, Jimma Geneti, District

Posted Date: March 4th, 2021

DOI: https://doi.org/10.21203/rs.3.rs-267187/v1

License: (9) This work is licensed under a Creative Commons Attribution 4.0 International License.

Read Full License

Version of Record: A version of this preprint was published at BMC Pediatrics on November 30th, 2021.

See the published version at https://doi.org/10.1186/s12887-021-03022-2. 


\section{Determinants of Diarrheal Diseases among Under Five Children in}

2 Jimma Geneti District, Oromia Region, Ethiopia, 2020: a case3 control study

4 Dejene Mosisa $^{1}$, Mecha Aboma $^{1 *}$, Teka Girma ${ }^{1}$, Abera Shibru $^{1}$

$5{ }^{1}$ Department of Public Health, Medicine and Health Sciences College, Ambo University, 6 Ambo, Ethiopia

$7 \quad *$ Corresponding author

8 Email address:

9 Mecha Aboma: abomamecha@gmail.com; P.O.BOX:19; Mobile: +251912060826

10 Abstract

11 Background: Globally, in 2017, there are nearly 1.7 billion cases of childhood diarrheal 12 diseases and it is the second most important cause of morbidity and mortality among under-five children in low-income countries including Ethiopia. Sanitary conditions, Poor

14 housing, unhygienic environment, inadequate safe water supply, cohabitation with domestic animals that may carry human pathogens, and lack of storage facilities for food combining with socio-economic and behavioral factors are the common determinates of diarrhea diseases and had a large impact on diarrhea incidence in most of the developing countries

Methods: A Community-based unmatched case-control study design was conducted on 407 systematically sampled under-five children of Jimma Geneti District (135 with diarrhea and 272 without diarrhea) from May 01 to 30, 2020. Data was collected using an interview administered questionnaire and observational checklist adapted from the 
WHO/UNICEF core questionnaire and other related literature. Descriptive, bivariate, and multivariate binary logistic regression analysis were done by using SPSS version 20.0

Result: Socio-demographic determinants such as being a child of 12-23 months age (AOR 3.3, 95\% CI 1.68-6.46) and parents/legal guardian's history of diarrheal diseases (AOR 7.38, 95\% CI 3.12-17.44) were significantly associated with diarrheal diseases among under-five children. Environmental and Behavioral factors such as unavailability of handwashing facility nearby latrine (AOR 5.22, 95\% CI 3.94-26.49), lack of hand-washing practice at critical times (AOR 10.6, 95\% CI 3.74-29.81), improper domestic solid waste disposal practice (AOR 2.68, 95\% CI 1.39-5.18) and not vaccinated against rotavirus (AOR 2.45, 95\% CI 1.25-4.81) were found important determinants of diarrheal diseases among under-five children.

Conclusion: Unavailability of hand-washing facility nearby latrine, parent's/legal guardian's history of last two weeks diarrheal diseases, improper latrine utilization, lack of hand-washing practice at critical times, improper solid waste disposal practices, and rotavirus vaccination status were the determinants of diarrheal diseases among under-five children identified in this study. Thus, promoting households through the provision of continuous and modified health information on the importance of sanitation, personal hygiene as well as vaccination against rotavirus, which is fundamental to decrease the burden of diarrheal disease among under-five children.

Key words: Unmatched, Case-Control, Determinants, Diarrhea, Jimma Geneti, District

\section{Back ground}

The World health organization (WHO) define diarrhea as the passage of three or more loose or liquid stools per day due to abnormally high fluid content of stool or an abnormal increase in daily stool fluidity, frequency, and volume from what is considered normal for an individual and caused by bacterial, viral, protozoa, and parasitic organisms (1). 
48 Rotavirus and Escherichia coli are the two mainly common etiological agents of moderateto-severe diarrhea in low-income countries (2). It is more common when there is a lack of adequate sanitation and hygiene and safe water supply for drinking, cooking, and cleaning, improper feeding practices, and poor housing situation (3).

Globally, in 2017, a large number of mortality and an estimated 1.7 billion diarrhea episodes occurred annually among under-five children. Despite the global achievement in the reduction of all-cause of diarrheal diseases particularly mortality in the past 30 years, worldwide diarrhea remains the second most important cause of death due to infections among children under five years of age. And it is responsible for killing around 760,000 children every year and about 2,195 children every day and around 1 in 9 child deaths. It is more than the death of children due to Acquired Immune deficiency syndrome (AIDS), malaria, and measles combined(1,4).

Similarly, diarrheal disease is the most important community health problem in SubSaharan Africa and was accountable for greater than $50 \%$ of childhood illnesses and $50-$ $80 \%$ of childhood death in the county $(5,6)$. Diarrheal diseases are one of the main leading causes of under-five illness, death and, under-nutrition in emerging countries. Averagely per year, every single child suffers from five episodes of diarrhea in African regions including Ethiopia (7). In spite of different continual efforts, 15,000 under five years of age children die every year due to diarrheal diseases related to inadequate environmental sanitation and hygiene practices (8). Ethiopia is one of the emerging sub-Saharan-African regions contributing to the tall burden of diarrheal illness and death (9).

In the year 2016 alone, generally, 1 in every 15 children die before reaching the fifth birthday, among these deaths, diarrhea kills almost fifteen thousand under-five children in Ethiopia (8). These were due to living conditions, high incidence of illness, lack of safe drinking water supply, sanitation and, hygiene, as well as poorer overall health and 
nutritional status (6). Poor sanitation, lack of access to clean water supply, and inadequate personal hygiene are accountable for $90 \%$ of diarrheal disease occurrence, this problem can be easily improved by health promotion and education (10).

In spite of all advances in health technology, improved management, and increased use of oral rehydration therapy in the past decades, diarrheal diseases still continue to be a major cause of morbidity and mortality and there is no dramatically changed evidence whether the health extension strategy has been made an effect on the risk factors of childhood diarrhea (11). And studies done in different parts of Ethiopia had shown that diarrhea is still a major public health concern $(12,13)$.

According to Ethiopia Demographic and Health Surveys (EDHS), under-five mortality declined from 166 deaths per 1,000 live births in 2000 to 67 deaths per 1,000 live births in 2016. This represents a $60 \%$ decrease in under-five mortality over a period of 16 years. According to this survey, the prevalence of diarrheal disease in under-five children in the 2 weeks before the survey has dropped from $13 \%$ in 2011 to $12 \%$ in 2016 . But, the underfive mortality rate in the Oromia region was 79 per 1000, which is higher than the national figure (8).

Additionally, as Jimma Geneti district Health Office performance report on the first quarter of 2019/2020 showed, the prevalence of diarrheal diseases among under-five children is $13.5 \%$. Despite the emphasis given by the Ethiopian ministry of health, respective regional health offices, Zonal department, and district health offices to improve child health, still many children are dying due to diarrheal disease in Ethiopia and specifically in Jimma Geneti district(14). Therefore, identifying the determinants of 
health implication for suitable interventions and appropriate strategies to decrease the impact of diarrheal disease (Figure 1).

Conceptual Frame Work

\section{Socio-Demographic factors}

$\checkmark$ Age of child

$\checkmark$ Sex of child

$\checkmark$ Occupational status of parents/legal gui

$\checkmark$ Educational status of parents/legal guar

$\checkmark$ Number of children in the family

$\checkmark$ parents/legal guardians history of diarrl

$\checkmark$ Place of birth of child

$\checkmark$ Relation of respondents to child

$\checkmark$ Parents/legal guardians age

$\checkmark$ Birth order

$\checkmark$ Relative wealth to other

$\checkmark$ Family size

\begin{tabular}{|c|c|c|}
\hline $\begin{array}{l}\text { Environmental } \\
\text { factors } \\
\checkmark \text { Availability of latrine } \\
\checkmark \text { Type of latrine } \\
\checkmark \text { Sources of water } \\
\checkmark \text { Time spent to collect } \\
\quad \text { water } \\
\checkmark \text { Hand washing facilities } \\
\checkmark \text { Waste disposal facility } \\
\checkmark \text { Floor of the room } \\
\checkmark \text { Houses shared with } \\
\quad \text { domestic animals }\end{array}$ & $\begin{array}{l}\text { Diarrhe } \\
\text { al } \\
\text { among } \\
\text { Under- } \\
\text { five } \\
\text { children }\end{array}$ & $\begin{array}{l}\text { Behavioral factors } \\
\checkmark \text { Latrine utilization } \\
\checkmark \text { Hand washing practices at critical } \\
\text { time } \\
\checkmark \text { Feeding practice until } 6 \text { month } \\
\checkmark \text { Solid waste disposal practice } \\
\checkmark \text { Liquid waste disposal practice } \\
\checkmark \text { Vaccination status } \\
\checkmark \text { Water storage practice } \\
\checkmark \text { Water treatment practice } \\
\checkmark \text { Water drawing practice } \\
\checkmark \text { Feed the child leftover food } \\
\checkmark \text { Time at which breast milk } \\
\text { initiated }\end{array}$ \\
\hline
\end{tabular}

11 Figure 1: Conceptual framework on Determinants of Diarrheal Diseases among under-five

2 Children in Jimma Geneti district, Oromia regional state, Western Ethiopia, May, 2020

$(15,16)$

Methods and Materials 
116 The study was conducted in Jimma Geneti District, from May 01 to 30, 2020. Jimma

117 Geneti District is located in Horo Guduru Wollega Zone, Oromia Region, the western part 118 of Ethiopia, 273km from the Capital City, Addis Ababa. Jimma Geneti district has a total 119 population of 90,364 which are 44,278 males and 46,086 females among which 5,755 $120(6.4 \%)$ urban and 84,609 (93.6\%) rural and 18,826 total households.There are 19,998 121 women of reproductive age and 14,848 under-five children (14) (Figure 2).

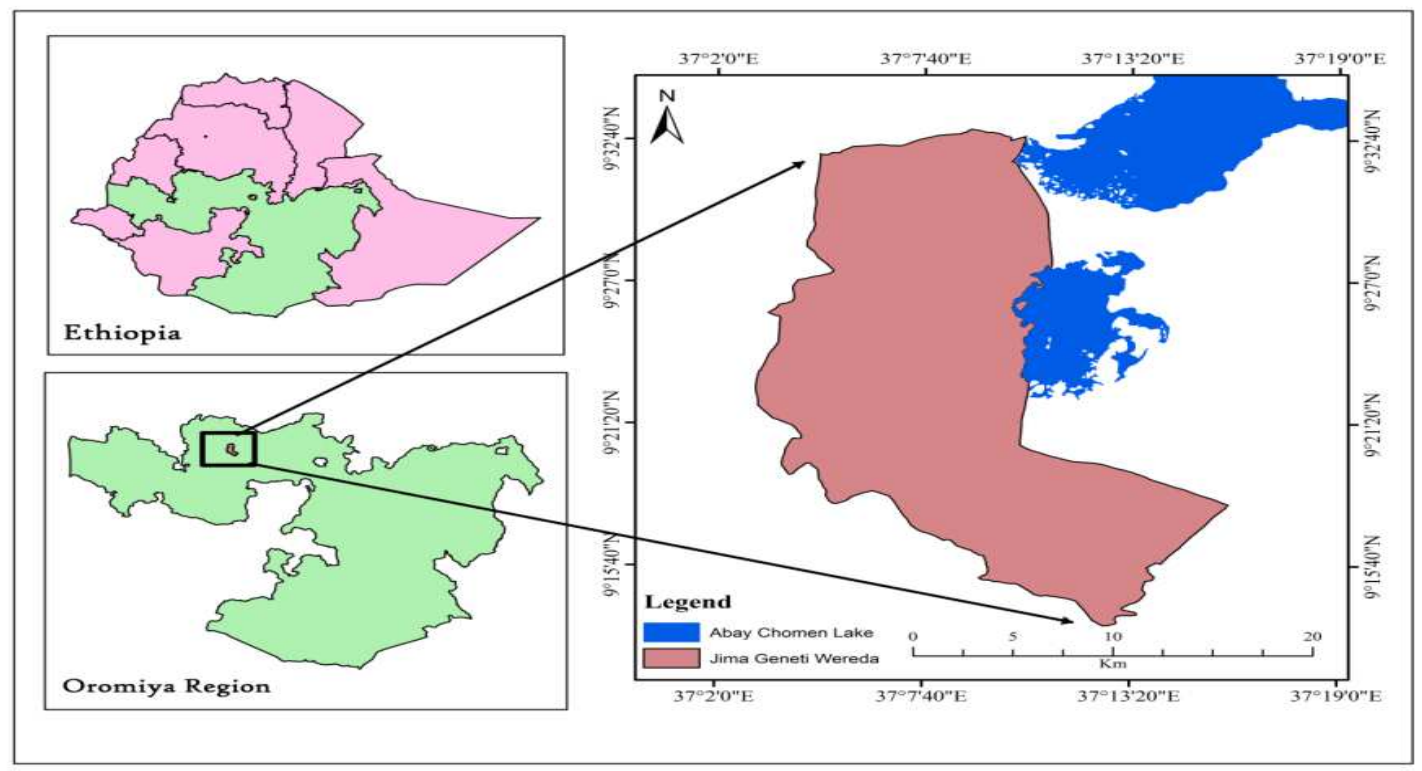

Figure 2: Location map of Jimma Geneti District: Nation, Region and, District, Oromia Regional state, Western Ethiopia, May, 2020 (14).

\section{Study Design Sample Size and Sampling Procedures}

126 A community-based unmatched case-control study design was conducted to assess determinants of diarrheal diseases among under-five children. The households who had under-five years old children and residents of the study area in randomly selected kebele was a sampling unit of this study while randomly selected under-five children with diarrhea for cases and without diarrhea for controls were the study unit of this study. 
131 Randomly selected under-five children in the households, with a report of diarrhea in the 132 preceding two weeks before the survey, were cases while randomly selected under-five 133 children in the households, without report of diarrhea in the preceding two weeks before 134 the survey, were controls

135 The sample size was determined using unmatched case-control of OpenEpi with the assumptions of power $=80 \%$; confidence level $=95 \%$; case to control ratio $=1: 2 ; \mathrm{P} 1=$ proportion of diarrheic children that had not used latrine for disposal of child feces, $\mathrm{P} 2=$ proportion of children non-diarrheic that had not used latrine for disposal of child feces as the main predictors of the outcome which was $33.0 \%$ and $19.1 \%$ among cases and controls respectively (12). And an adjusted odds ratio $(\mathrm{AOR}=2.09)$ and $10 \%$ of none response rates were considered. Finally, 407 (135 from cases and 272 from controls) sample size was generated. The district had 14 kebeles (small unit of administration) and from these 4 kebeles were selected by lottery method. Cases and controls were identified by the census, then a total of 3745 households with under-five children (156 with diarrhea and 3589 without diarrhea) in the selected kebeles were registered and coded through a house-tohouse survey. Afterward, the calculated sample size for control was proportionally allocated to the size of households with under-five children for each selected kebeles. Finally, a total of 272 controls were selected by using the systematic random sampling technique, and all of the registered 135 cases were taken and included in the study (Fig 3). 

principal investigator on the study instruments and consent form, how to interview and,

Jimma Ganati District (14 Sub-districts)

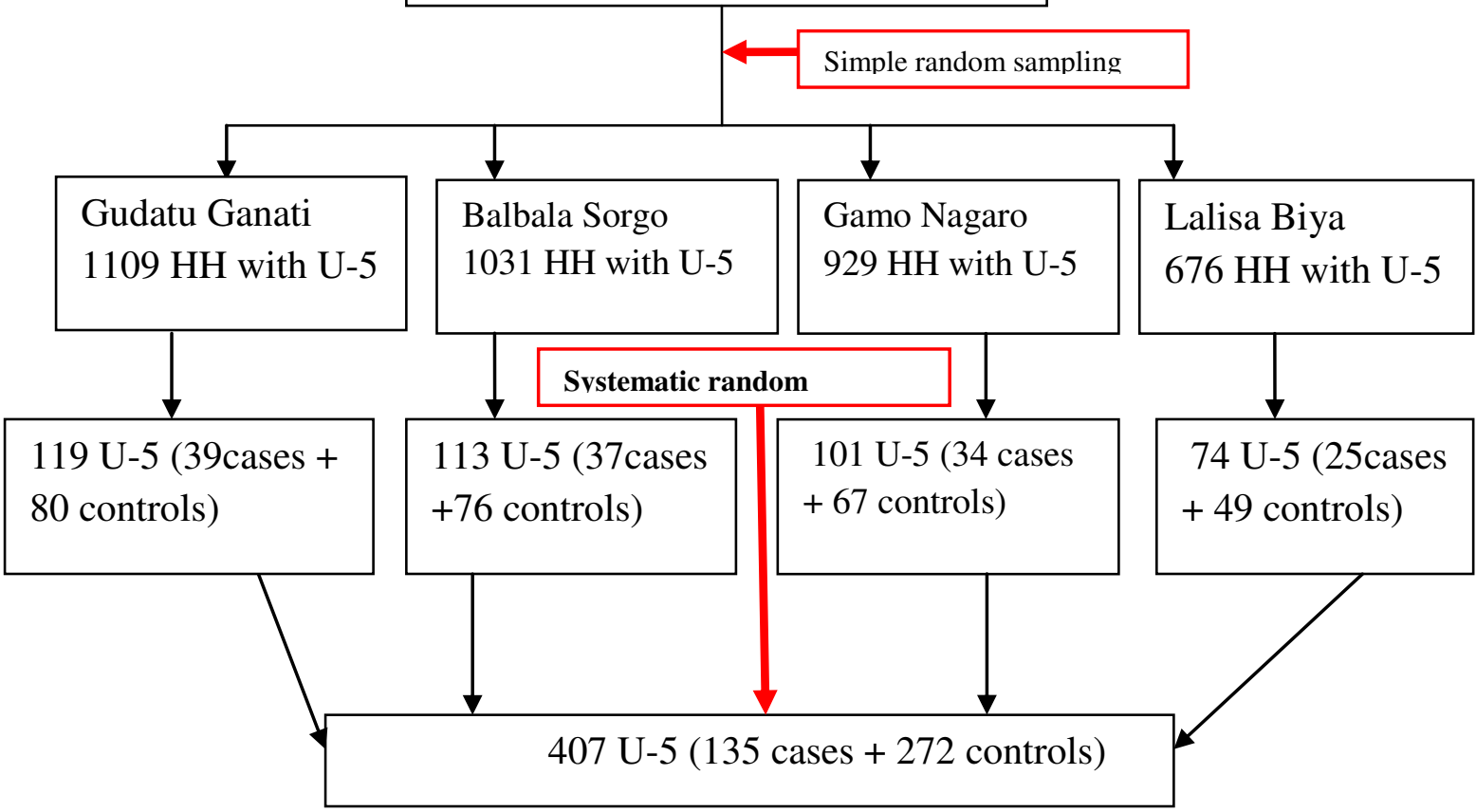

Figure 3: Diagrammatic presentation of sampling technique of under-five children in Jimma Geneti district, Oromia Regional state, Western Ethiopia, May, 2020.

\section{Data Collection Tool and Personnel}

Data were collected by eight trained BSc Nurses under the supervision of four Health officers using a pretested structured questionnaire adapted from the WHO/UNICEF core questionnaire and other related literature $(15,16,17)$. In addition, an observational checklist was used to observe water storage containers, the presence or absence of feces around the latrine and compound, availability, and types of the latrine, and the presence or absence of handwashing facilities nearby the latrine.

\section{Data Quality control and Analysis}

Data quality was assured through pre-test on $5 \%$ of the total sample size in different subdistricts of the study area. Data collectors and supervisors were trained for one day by the data collection procedures. The data collection processes were closely supervised by 
supervisors and investigators. Before data entry, the questionnaires were checked for completeness, consistency, and correction measures made by supervisors and investigators. Then, the data were coded and entered into Epi Info and was exported to SPSS for data processing, cleaning, and analysis. Descriptive analysis like frequency and percentage was carried out to describe socio-demographic characteristics of the respondents and environmental and behavioral determinants of diarrhea among under-five children and results were presented in texts and tables. The bivariate and multivariate analyses were done using binary logistic regression to identify factors associated with diarrheal diseases among under-five children. Candidate variables for the final model (multivariate binary logistic regression) were identified using binary logistic regression model at a p-value less than 0.25 and the final model multiple logistic regression was done to see the independent effect of each explanatory variable on the study variable at a pvalue of less than 0.05 .

The Hosmer and Lemeshow goodness-of-fit $(\mathrm{P}$-value $=0.348)$ was checked to test for model fitness. The independent variables were tested for multi co-linearity using the Variance Inflation Factor (VIF) and the Tolerance tests and no variables found to have VIF greater than 2 to be omitted from the analysis.

\section{Terms and Operational Definition}

Diarrhea: is defined as having three or more loose or watery stool in a 24 hour period in the household within the two weeks period before the survey administered as reported by the parents/legal guardians of the child (8).

Parents/legal guardians: mother/father/caregiver or a person who is responsible for taking care of a child; the person can be a male or female relative of the child or nonrelative. 
Relative Wealth to other: Households is categorized based on the number and kinds of domestic animals they own, ranging from a hen to cow/ox, in addition to farmland ownership with the amount of productivity per year and housing characteristics such as consumer goods, toilet facilities, and flooring materials. Ranking each household by their living standard, and then dividing the distribution into three categories Model, Middle, and poor (18).

212 Improved water sources: It includes piped water into the dwelling, piped water to the yard, tube well, or borehole, public standpipes, protected dug wells, protected springs, and rainwater. An improved source is one that is likely to provide "safe" water (4).

Improper waste disposal: is the disposal of waste in a way that has an impact on the environment. Examples include littering, hazardous waste that is dumped into the ground, and not recycling and disposing of a refuses in open fields (4).

Hand washing during the critical time: refers to parents'/legal guardians' hand-washing practice after utilization of latrine, after helping your child defecates, before food preparation, and before self-feeding and child-feeding. If yes for all critical times of handwashing, it concluded as good, otherwise poor practice.

Proper latrine utilization: Households with functional latrines and at least no observable feces in the compound, observable fresh feces through the squat hole, and the foot-path to the latrine were uncovered with grasses.

Good awareness towards diarrhea: Respondents who mentioned at least three causes of diarrhea such as microorganisms, flies, contaminated food/water, three ways of transmission such as by eating contaminated food, by flies, and by physical contact with the diseased person and its prevention such as vaccination of rotavirus vaccine, early 
initiation, and exclusive breastfeeding, use safe water for drinking and food preparation, proper waste disposal.

\section{Results}

\section{Socio-demographic Characteristics of Study Participants}

233

234

235

Totally, 407 under five-children (135 cases and 272 controls) were sampled for this study. However, data were gathered from 399 under-five children of study participants (127 among cases and 272 among controls) made a response rate of $98.03 \%$ in both study groups. Among those studied children, 76 (59.8\%) of cases and $156(57.4 \%)$ of controls were male children and $44(34.6 \%)$ cases and $128(47.1 \%)$ controls were found in the age group of 24-59 months. The mean (+SD) of the age of cases and controls was $18.79(+5.2)$ and $21.09(+5.9)$ months respectively. Among these children, $107(84.3 \%)$ of cases and $231(84.9 \%)$ of controls were born at the health facility.

Of all parents/legal guardians 118 (92.9\%) among cases and 266 (97.8\%) among controls were biological mothers. Out of the total parents/legal guardians 106 (81.9\%) cases and $247(87.9 \%)$ controls were found in the age group of 25-35 years.

The majority of parents/legal guardians, in both groups, 108 (85\%) cases, and 201 (73.9\%) controls were housewives by occupation. Most of parents/legal guardians, 115 (90.6\%) cases, and $255(93.8 \%)$ controls were married. More than half of the parents/legal guardians in both study groups; $69(54.3 \%)$ cases and $151(55.5 \%)$ controls had no formal education

Out of the total, $90(70.9 \%)$ parents/legal guardians of the cases and $196(72.1 \%)$ of the controls were protestant religion followers. About, $126(99.2 \%)$ of cases and $267(98.2 \%)$ of controls were from Oromo by ethnicity. 
252 Regarding the family size of the households in both groups, 62 (48.8\%) of cases and 139

$253(51.1 \%)$ of controls were had $>=5$ members and the number of under-five children in the

254 households in both groups was one among more than half of the households, $65(51.2 \%)$ of

255 cases and $153(56.2 \%)$ of controls.

256 Among all households, 34 (26.8\%) parents/legal guardians of cases, and 14 (5.1\%)

257 parents/legal guardians of controls had last two-week history of diarrheal (Table 1).

258 Table 1: Socio-demographic characteristics of study participants in Jimma Geneti District,

259 Oromia Regional state, Western Ethiopia, May, 2020

\begin{tabular}{|c|c|c|}
\hline Socio-demographic & \multicolumn{2}{|c|}{ Frequency } \\
\hline $\begin{array}{l}\text { characteristics of study } \\
\text { participants }(\mathrm{n}=399)\end{array}$ & $\begin{array}{c}\text { Number/Percent of } \\
\text { cases of cases }(n=127)\end{array}$ & $\begin{array}{c}\text { Number/Percentage of } \\
\text { controls }(n=272)\end{array}$ \\
\hline \multicolumn{3}{|l|}{ Sex of Child } \\
\hline Male & $76(59.8)$ & $156(57.4)$ \\
\hline Female & $51(40.2)$ & $116(42.6)$ \\
\hline \multicolumn{3}{|l|}{ Age of child } \\
\hline $0-5$ months & $12(9.4)$ & $17(6.3)$ \\
\hline 6-11months & $27(21.3)$ & $48(17.6)$ \\
\hline 12-23 months & $44(34.6)$ & $79(29)$ \\
\hline 24-59 months & $44(34.6)$ & $128(47.1)$ \\
\hline \multicolumn{3}{|l|}{ Place of Delivery } \\
\hline Health facility & $107(84.3)$ & $231(84.9)$ \\
\hline Home & $20(15.3)$ & $41(15.1)$ \\
\hline \multicolumn{3}{|l|}{ Age of the respondents } \\
\hline 18-24 years & $2(1.6)$ & $9(3.3)$ \\
\hline
\end{tabular}




\begin{tabular}{|c|c|c|}
\hline $25-35$ years & $104(81.9)$ & $239(87.9)$ \\
\hline$>35$ years & $21(16.5)$ & $24(8.8)$ \\
\hline \multicolumn{3}{|l|}{ Relation of the respondents } \\
\hline Mother & $118(92.9)$ & $266(97.8)$ \\
\hline Caregiver & $9(7.1)$ & $6(2.2)$ \\
\hline \multicolumn{3}{|l|}{ Ethnicity of respondents } \\
\hline Oromo & $126(99.2)$ & $267(98.2)$ \\
\hline Amhara/other & $1(0.8)$ & $5(1.8)$ \\
\hline \multicolumn{3}{|l|}{ Marital status } \\
\hline Married & $115(90.6)$ & $255(93.8)$ \\
\hline Single & $10(7.9)$ & $11(4)$ \\
\hline Divorced/Widowed & $2(1.6)$ & $6(2.2)$ \\
\hline \multicolumn{3}{|l|}{ Education status } \\
\hline No formal Education & $69(54.3)$ & $151(55.5)$ \\
\hline Grade 1-8 & $39(30.7)$ & $63(23.2)$ \\
\hline Grade 9-12 & $13(10.2)$ & $34(12.5)$ \\
\hline Grade12+ & $6(4.7)$ & $24(8.8)$ \\
\hline \multicolumn{3}{|l|}{ Occupational status } \\
\hline Housewife & $108(85.0)$ & $201(73.9)$ \\
\hline Government employee & $3(2.4)$ & $18(6.6)$ \\
\hline Private/other & $16(12.6)$ & $53(19.5)$ \\
\hline \multicolumn{3}{|l|}{ No of U-5 children in $\mathrm{HH}$} \\
\hline 1 & $65(51.2)$ & $153(56.2)$ \\
\hline$>=2$ & $62(48.8)$ & $119(43.8)$ \\
\hline
\end{tabular}




\begin{tabular}{|c|c|c|}
\hline Relative wealth to other & & \\
\hline Poor & $25(19.7)$ & $59(21.7)$ \\
\hline Middle & $65(51.2)$ & $140(51.5)$ \\
\hline Model & $37(29.1)$ & $73(26.8)$ \\
\hline $\begin{array}{c}\text { Parents/legal guardians hist } \\
\text { of diarrhea }\end{array}$ & & \\
\hline Yes & $34(26.8)$ & $14(5.1)$ \\
\hline No & $93(73.2)$ & $258(94.9)$ \\
\hline
\end{tabular}

\section{Environmental related characteristics of study participants respondents}

The majority of households, $117(92.1 \%)$ among cases and 258 (94.9\%) among controls had latrine facilities in their compound. From these households that had latrines, more than half, $66(56.4 \%)$ among cases and 160 (62.0\%) among controls were used pit latrine without a slab.

About $92(72.4 \%)$ of cases and $201(73.9 \%)$ of controls of households were used improved sources of water supply and $36(28.3 \%)$ of cases and $87(32.0 \%)$ of controls of households were traveled greater than thirty minutes to collect water from the sources.

More than half of households latrines, 73 (57.5\%) of cases and 163 (59.9\%) of controls had the hand-washing facility and $70(55.1 \%)$ of cases and $163(59.9 \%)$ of controls had a waste disposal facility in their compound.

272 The majority of the floor of houses of the households, 94 (74.0\%) of cases, and 214 $273(78.7 \%)$ of controls were made of soil. About $112(88.2 \%)$ of cases and $258(84.9 \%)$ of controls of households had separated kitchen from their houses. From the total households, 
$104(81.9 \%)$ from the cases and $251(92.3 \%)$ from the controls were not shared houses with domestic animals (Table 2).

277 Table 2: Environmental related characteristics of study participants in Jimma Geneti

278 District, Oromia Regional State, Western Ethiopia, May, $2020(n=399)$

\begin{tabular}{|c|c|c|}
\hline \multirow{2}{*}{$\begin{array}{l}\text { Environmental related characteristics } \\
\text { of study participants }(\mathrm{n}=399)\end{array}$} & \multicolumn{2}{|c|}{ Frequency } \\
\hline & $\begin{array}{c}\text { Number/percent of } \\
\text { cases of cases }(n=127)\end{array}$ & $\begin{array}{c}\text { Number/percentage of } \\
\text { controls }(n=272)\end{array}$ \\
\hline \multicolumn{3}{|l|}{ Latrine availability } \\
\hline Yes & $117(92.1)$ & $258(94.9)$ \\
\hline No & $10(7.9)$ & $14(5.1)$ \\
\hline \multicolumn{3}{|l|}{ Types of latrine } \\
\hline Pit latrine without slab & $66(56.4)$ & $160(62.0)$ \\
\hline Pit latrine with slab & $7(6.0)$ & $41(16.0)$ \\
\hline Ventilated improved pit latrine & $44(37.6)$ & $57(22.0)$ \\
\hline \multicolumn{3}{|l|}{ Sources of water } \\
\hline Improved & $92(72.4)$ & $201(73.9)$ \\
\hline Unimproved & $35(27.6)$ & $71(26.1)$ \\
\hline \multicolumn{3}{|l|}{ Time spent to collect water } \\
\hline$</=30 \mathrm{~min}$ & $91(71.7)$ & $185(68.0)$ \\
\hline$>30 \mathrm{~min}$ & $36(28.3)$ & $8732.0)$ \\
\hline \multicolumn{3}{|l|}{ Availability of hand washing facility } \\
\hline Yes & $73(57.5)$ & $173(63.6)$ \\
\hline No & $54(42.5)$ & $99(36.4)$ \\
\hline Availability of waste disposal & & \\
\hline
\end{tabular}




\begin{tabular}{|c|c|c|}
\hline facility & & \\
\hline Yes & $70(55.1)$ & $163(59.9)$ \\
\hline No & $57(44.9)$ & $109(40.1)$ \\
\hline Ownership status of the house & & $219(80.5)$ \\
\hline Private & $103(81.1)$ & $53(19.5)$ \\
\hline Rented & $24(18.9)$ & $214(78.7)$ \\
\hline Floor of house & & $17(6.3)$ \\
\hline Soil & $94(74.0)$ & $41(15.1)$ \\
\hline Wood & $3(2.4)$ & $258(84.9)$ \\
\hline Cement & $30(23.6)$ & $14(5.1)$ \\
\hline Availability of separated kitchen & & \\
\hline Yes & $112(88.2)$ & \\
\hline No & $15(11.8)$ & \\
\hline Yes & & \\
\hline No & & \\
\hline Houses shared with domestic & & \\
\hline animals & & \\
\hline Bes. & & \\
\hline
\end{tabular}

279 Behavioral Characteristics of study participants

280 Regarding behavioral characteristics majority of households 75 (59.1\%) among cases, and $281220(80.9 \%)$ among controls were properly practiced latrine utilization. Greater than three 282 fourth, $102(80.3 \%)$ among cases and 265 (97.4\%) among controls of respondents have washed their hands at critical times. Sixty-four (50.4\%) of households from cases and 176 (64.7\%) of households from controls were disposed domestic solid refuse properly while $65(51.2 \%)$ from cases and $113(41.5 \%)$ from controls were disposed of liquid waste improperly. 
More than half of under-five children, 73 (62.9\%) from cases and 198 (77.6\%) from controls were vaccinated for the measles vaccine. And $73(57.5 \%)$ of cases and 208 (76.5\%) of controls were received rotavirus vaccine. From all parents/legal guardians, 78 diarrheal morbidity (Table 3).

292 Table 3: Behavioral characteristics of study participants in Jimma Geneti District, Oromia

Regional State, Western Ethiopia, May, 2020 (n=399).

\begin{tabular}{|c|c|c|}
\hline \multirow{2}{*}{$\begin{array}{l}\text { Behavioral characteristics of study } \\
\text { participants }(\mathrm{n}=399)\end{array}$} & \multicolumn{2}{|c|}{ Frequency } \\
\hline & $\begin{array}{c}\text { Number/Percentage of } \\
\text { cases }(n=127)\end{array}$ & $\begin{array}{l}\text { Number/Percentage } \\
\text { of controls }(n=272)\end{array}$ \\
\hline \multicolumn{3}{|l|}{ Latrine Utilization } \\
\hline Proper utilization & $75(59.1)$ & $220(80.9)$ \\
\hline Improper utilization & $52(40.9)$ & $52(19.1)$ \\
\hline \multicolumn{3}{|l|}{ Hand washing at critical time } \\
\hline Yes & $102(80.3)$ & $265(97.4)$ \\
\hline No & $25(19.7)$ & $7(2.6)$ \\
\hline \multicolumn{3}{|l|}{ Feeding practice until 6 months } \\
\hline Exclusive breastfeeding & $99(78.0)$ & $245(90.1)$ \\
\hline Mixed feeding & $26(20.5)$ & $24(8.8)$ \\
\hline Formula feeding & $2(1.6)$ & $3(1.1)$ \\
\hline \multicolumn{3}{|l|}{ Feed the child leftover food } \\
\hline Yes & $13(10.2)$ & $15(5.5)$ \\
\hline No & $114(89.8)$ & $257(94.5)$ \\
\hline Solid waste disposal & & \\
\hline
\end{tabular}




\begin{tabular}{|c|c|c|}
\hline Proper & $64(50.4)$ & $176(64.7)$ \\
\hline Improper & $63(49.6)$ & $96(35.3)$ \\
\hline \multicolumn{3}{|c|}{ Liquid waste refusal } \\
\hline Proper & $62(48.8)$ & $159(58.5)$ \\
\hline Improper & $65(51.2)$ & $113(41.5)$ \\
\hline \multicolumn{3}{|l|}{ Measles Vaccine } \\
\hline Vaccinated & $73(62.9)$ & $198(77.6)$ \\
\hline Unvaccinated & $43(37.1)$ & $57(22.4)$ \\
\hline \multicolumn{3}{|l|}{ Rotavirus Vaccine } \\
\hline Vaccinated & $73(57.5)$ & $208(76.5)$ \\
\hline Unvaccinated & $54(42.5)$ & $64(23.5)$ \\
\hline \multicolumn{3}{|c|}{ Water treatment at home } \\
\hline Yes & 49 (38.6) & $154(56.6)$ \\
\hline No & $78(61.4)$ & $118(43.4)$ \\
\hline \multicolumn{3}{|c|}{ Ways of collected water drawn } \\
\hline By dipping & $22(17.3)$ & $33(12.1)$ \\
\hline By pouring & $105(82.7)$ & $239(87.9)$ \\
\hline \multicolumn{3}{|c|}{ Time of initiating breastfeeding } \\
\hline Within one hour & $103(81.1)$ & $231(84.9)$ \\
\hline After one hour & 24 (18.9) & $41(15.1)$ \\
\hline \multicolumn{3}{|c|}{ Awareness towards diarrhea } \\
\hline Good & 78 (61.4) & $171(62.9)$ \\
\hline Poor & 49 (38.6) & $101(37.1)$ \\
\hline
\end{tabular}


296 Socio-demographic characteristics of the respondents, environmental factors, and

297 behavioral factors were analyzed with bivariate logistic regression to see the factors 298 associated with diarrheal diseases among under-five children. Bivariate logistic regression 299 analysis showed the age of the child, the age of parents/legal guardians, the relation of 300 respondents to the child, marital status, educational status, occupational status, availability 301 of handwashing facility nearby latrine, types of the floor of the house of households, availability of separated kitchen, parents/legal guardians last two weeks history of diarrhea, latrine utilization, hand washing practice at a critical time, feeding practice until 6 months, feeding the child with leftover food, domestic solid/liquid waste disposal practice, the status of measles and rotavirus vaccine, homemade drinking water treatment, ways of collected water drawn from storage and house of households shared with domestic animals were factors associated with diarrheal diseases among under-five children. Variables that were associated with diarrheal diseases among under-five children at Pvalue, less than 0.25 in the bivariate binary logistic regression analysis were included in multivariate binary logistic regression analysis to identify the independent predictors of diarrheal diseases among under-five children. Age of child, availability of hand-washing facility nearby latrine, parents/legal guardians history of last two weeks diarrheal disease, latrine utilization, hand-washing practice during a critical time, domestic solid waste refusal practice, and rotavirus vaccination status was found significantly associated with diarrheal diseases among under-five children at a p-value less than or equal to 0.05 . The odds of developing the diarrheal disease among under-five children were 2.5 and 3 times higher among children of age 6-11 and 12-23 months respectively as compared to children of age 24-59 months $(\mathrm{AOR}=2.46$; 95\%CI: $1.09-5.57$ and $\mathrm{AOR}=3.3 ; 95 \% \mathrm{CI}$ : $1.68-6.46)$. 
320 Odds of developing the diarrheal disease among under-five children from households who 321 had no hand-washing facility near their latrine were 5 times higher when compared to counterparts $(\mathrm{AOR}=5.2 ; 95 \% \mathrm{CI}: 3.94-26.49)$. Under-five children whose parents'/legal guardians' had a history of diarrheal disease in the last two weeks had 7 times more likely to developed the diarrheal disease as compared with their counterparts $(\mathrm{AOR}=7.38$; 95\%CI: 3.12- 17.44)

The odds of developing the diarrheal disease among under-five children was about 2 times higher among households who had not utilized latrine properly when compared to households who have properly utilized latrine (AOR=2.34; 95\%CI: $1.16,4.75)$. The odds of developing the diarrheal disease were 10.6 times higher among under-five children whose parents'/legal guardians' did not wash their hands during critical time compared with under-five children whose parents'/legal guardians' did wash their hands during critical times $(\mathrm{AOR}=10.6 ; 95 \% \mathrm{CI}: 3.7-29.8)$.

Odds of developing the diarrheal disease among under-five children whose parents'/legal guardians' practiced improper domestic solid waste disposal were about 2.7 times higher than under-five children whose parents'/legal guardians' practiced proper domestic solid waste disposal $(\mathrm{AOR}=2.68 ; 95 \% \mathrm{CI}: 1.39-5.18)$.

Unvaccinated under-five children were 2.5 times more likely to develop diarrhea disease compared to rotavirus vaccinated children, $(\mathrm{AOR}=2.45 ; 95 \% \mathrm{CI}: 1.25-4.81)($ Table 4$)$.

Table 4: Determinants of diarrheal disease among under-five children in Jimma Geneti

District, Oromia Regional State, Western Ethiopia, May 2020 (n=399)

\begin{tabular}{|l|c|c|c|c|c||}
\hline \multirow{3}{*}{ Variables } & \multicolumn{5}{|c|}{ Diarrheal diseases status among under-five children } \\
\cline { 2 - 6 } & Case= & Control= & & P- \\
& 127, & 272, & COR (95\%CI) & AOR (95\%CI) & Value \\
\hline
\end{tabular}




\begin{tabular}{|c|c|c|c|c|c|}
\hline & № (\%) & № (\%) & & & \\
\hline \multicolumn{6}{|l|}{ Age of child } \\
\hline $0-5$ months & $12(9.4)$ & $17(6.3)$ & $1.88(0.82,4.33)+$ & $1.48(0.61,3.61)$ & .387 \\
\hline 6-11months & $27(21.3)$ & $48(17.6)$ & $1.64(0.91,2.93)+$ & $2.46(1.09,5.57)^{*}$ & .030 \\
\hline $12-23$ months & 44 (34.6) & $79(29)$ & $1.66(1.00,2.74)^{*}$ & $3.30(1.68,6.46)^{*}$ & .001 \\
\hline 24-59 months & 44 (34.6) & $128(47.1)$ & 1.00 & & \\
\hline \multicolumn{6}{|l|}{ Relation } \\
\hline Mother & $118(92.9)$ & $266(97.8)$ & 1.00 & 1.00 & \\
\hline Caregiver & $9(7.1)$ & $6(2.2)$ & $3.38(1.18,9.72)^{*}$ & $0.58(0.32,1.06)$ & .073 \\
\hline $\begin{array}{c}\text { Hand washing } \\
\text { facility }\end{array}$ & & & & & \\
\hline Yes & $73(57.5)$ & $173(63.6)$ & 1.00 & 1.00 & \\
\hline No & $54(42.5)$ & 99 (36.4) & $1.29(0.84,1.99)+$ & $5.2(3.94,26.49) * *$ & $<.001$ \\
\hline $\begin{array}{c}\text { Parental/legal } \\
\text { guardians' } \\
\text { history of } \\
\text { diarrhea }\end{array}$ & & & & & \\
\hline Yes & $34(26.8)$ & $14(5.1)$ & $6.74(3.46,13.1)^{*}$ & $7.38(3.1,17.44) * * *$ & $<.001$ \\
\hline No & $93(73.2)$ & $258(94.9)$ & 1.00 & 1.00 & \\
\hline $\begin{array}{c}\text { Latrine } \\
\text { Utilization }\end{array}$ & & & & & \\
\hline Proper & $75(59.1)$ & $220(80.9)$ & 1.00 & 1.00 & \\
\hline Improper & $52(40.9)$ & $52(19.1)$ & $2.93(1.84,4.67)^{*}$ & $2.34(1.16,4.75)^{*}$ & .018 \\
\hline Critical time & & & & & \\
\hline
\end{tabular}




\begin{tabular}{|c|c|c|c|c|c|}
\hline \multicolumn{6}{|l|}{ Thand washing } \\
\hline Yes & $102(80.3)$ & $265(97.4)$ & 1.00 & 1.00 & \\
\hline No & $25(19.7)$ & $7(2.6)$ & $9.28(3.89,22.1)^{*}$ & $10.6(3.7,29.8)^{* * *}$ & $<.001$ \\
\hline \multicolumn{6}{|l|}{$\begin{array}{c}\text { Solid waste } \\
\text { disposal }\end{array}$} \\
\hline Proper & $64(50.4)$ & $176(64.7)$ & 1.00 & 1.00 & \\
\hline Improper & $63(49.6)$ & $96(35.3)$ & $1.81(1.18,2.77)^{*}$ & $2.68(1.39,5.18)^{*}$ & .003 \\
\hline $\begin{array}{l}\text { Rotavirus } \\
\text { Vaccine }\end{array}$ & & & & & \\
\hline Vaccinated & $73(57.5)$ & $208(76.5)$ & 1.00 & 1.00 & \\
\hline Unvaccinated & $54(42.5)$ & $64(23.5)$ & $2.40(1.53,3.77)^{*}$ & $2.45(1.25,4.81)^{*}$ & .009 \\
\hline \multicolumn{6}{|l|}{ Water treatment } \\
\hline Yes & $49(38.6)$ & $154(56.6)$ & 1.00 & 1.00 & \\
\hline No & $78(61.4)$ & $118(43.4)$ & $2.08(1.35,3.19)^{*}$ & $1.06(0.57,1.97)$ & .867 \\
\hline
\end{tabular}

Case $=$ under-five children with diarrhea, Control $=$ under-five children without diarrhea,

342 Crude odds ratio (COR), Adjusted odds ratio (AOR), Confidence interval (CI), P-value derived from multivariate logistic regression based on likelihood ratio test, significant CI

344 of the models are indicated in the bold letter, ${ }^{*} \mathrm{p}<0.05 ; * * \mathrm{p}<0.001$.

\section{Discussion}

The result of this study showed that child's age group 6-11 and 12-23 months were 2.5 and

3473 times more likely to develop diarrhea disease as compared to children of age group 2459 months respectively. In general, children age greater than 24 months had a lower risk of having diarrheal diseases than children whose ages between 6-23 months. This result was concurring with the result of other case-control studies conducted in Medebay Zane

351 District, Gobi District, and Rural Ethiopia (19, 20, and 21). 
352 Similarly, this result was consistent with the study reported from Indonesia and 353 Guatemala $(22,23)$. The likely explanation for this risk might be children between the ages 354 of 6-23 months are introduced to foods in addition to breast milk; this may expose their undeveloped immunity to infectious agents causing diarrheal diseases. Moreover, children at these ages are starting to crawl and walk, thus they may pick dirty or other contaminated objects and take them to their mouth. Likewise, the 2016 EDHS report revealed that diarrhea prevalence remains high $(18 \%)$ at the age of $12-23$ months, for the reason that mostly weaning and walking often occurs during these ages which contribute to the increased risk of contamination from the environments (8).

The unavailability of a hand-washing facility near the latrine was positively associated with childhood diarrheal disease. In this study, under five years old children from households that had no hand-washing facilities adjacent to the latrines were about 5 times more likely to have diarrheal diseases than under-five year's old children from households that have hand-washing facilities adjacent to the latrines. The result of this study was consistent with the study conducted in Jimma district and Yama Gulale (24, 25). This might be expressed as where the hand-washing facilities were not available; the parents/legal guardians lack the initiation to wash hands after toilet use and feed their children with hands contaminated with fecal matters which causes diarrheal diseases.

Additionally, the finding of this study showed that parents'/legal guardians' history of diarrheal diseases was significantly associated with diarrhea diseases among under-five children. Children whose parents/legal guardians had diarrheal diseases in the last 2 weeks prior to this study were 7 times more likely to develop diarrheal diseases than children whose parents/legal guardians had no history of diarrheal diseases in the last two weeks. The result of this study was similar to the study findings conducted in Ethiopia Harar Town, Medebay Zana District, and Pawi Hospital, Northwest Ethiopia $(13,19,26)$. The 
fact that parents/legal guardians are the most food handlers of the family and the main childcare providers; hence, the possibility of diarrheal diseases among children with parents/legal guardians who had diarrheal diseases is a usual event. It also indicates poor hygienic practice in the household results in the occurrence of diarrheal diseases among under-five children. This might be due to parents/legal guardians with diarrheal diseases were considered as a source of diarrhea diseases among under-five children. Moreover, this could be due to the care of the child might be under question if the parents/legal guardians got sick. According to WHO, globally an estimated $88 \%$ of diarrheal disease mortality were due to unsafe water supply, inadequate sanitation, and poor hygiene practices (1).

The result of this study also revealed that households who improperly utilized latrine were 2 times more likely at risk to develop diarrheal diseases among under-five children compared to households that utilized latrine properly. This result was comparable with the study finding reported from West Gojjam of Ethiopia (12) and Kawangware Slum in Nairobi County, Kenya (27). This indicated that proper latrine utilization had a significantly strong association with diarrheal morbidity. This showed that the presence of a latrine alone does not ensure the prevention of diarrheal diseases among under-five children unless properly utilized. When latrine properly utilized, many microorganisms that cause diarrheal diseases might be under control.

The finding of this study indicated that children from parents/legal guardians who did not practice hand washing during the critical time were affected with diarrheal disease 10.6 times more likely compared to those children whose parents/legal guardians have practiced hand washing during a critical time. This finding was in line with the studies conducted in Adama Rural and Harena Buluk woreda in Ethiopia $(28,29)$ and in Zambia (30). This might be indicated that since the parents/legal guardians were the main caregivers for their 
children they should wash their hands at a critical time to prevent diarrheal diseases.

403 Diarrheal diseases are largely spread through contaminated water and food supplies. This

404

405

406

407

408

409

410

411

412

413

414

415

416

417

418

419

420

421

422

423

424

425

426 contamination occurs mainly from inadequate hygiene and sanitation. Hand-washing with soap at a critical time has been shown to reduce the incidence of diarrheal disease by $40 \%$ (1).

The finding of this study revealed that improper domestic solid waste disposal practices were 2.7 times more likely at risk of developing diarrhea diseases compared to their counterparts. The result of this study was consistent with the studies conducted at Medebay Zana District and Jamma District in Ethiopia $(19,25)$ and in Kenya (27). This might be due to improper disposal of domestic solid waste serves as a source of infectious agents and reproduction sites of insects. As well improper domestic solid waste disposal practices create a favorable environment for flies that carry the pathogens and could be sources of contamination for water, food, and food utensils these might cause children exposed to contaminated environments and a leading risk factors for diarrheal diseases among under-five children.

The result of our study finding indicated that children who were not received the rotavirus vaccine were 2.5 times more likely to develop diarrheal diseases as compared to those children who were received the rotavirus vaccine. This finding was in line with the studies conducted at Harena Buluk Woreda, Bahir Dar, and Debre Berhan in Ethiopia $(31,28,32)$ and in sub-Saharan Africa, Cameroon, and Madagascar (33, 34). These findings were reported that the rotavirus vaccine showed a significant association with the occurrence of diarrheal diseases among under-five children. This revealed that the rotavirus vaccination is one of the best ways to prevent diarrheal morbidity and its consequences. Thus, twodose rotavirus vaccines should be given for children as part of a comprehensive approach to control diarrhea. Evidence from experts review on vaccines suggests that rotavirus 
427 vaccines effectiveness provide sufficient prevention against rotavirus episodes among 428 under-five children thus reducing the morbidity of diarrhea among this age group $(35,36)$.

\section{Limitation of the study}

430 One of the strengths of this study was conducted on community-based using case-control study design and using WHO/ UNICEF core-based standard questionnaire for data collection. Some behavioral practices including hand-washing practices at a critical time, reports of parent's/legal guardian's history of last two weeks period of diarrhea, and treatment of drinking water at home used in the analysis were self-reported by the respondents which might be introduced imprecision and recall bias. Lack of including social factors could be considered as an additional limitation of this study.

\section{Conclusion}

Unavailability of hand-washing facility nearby latrine, parent's/legal guardian's history of last two weeks diarrheal diseases, improper latrine utilization, lack of hand-washing practice at a critical time, improper solid waste disposal practices, and rotavirus vaccination status were the determinants of diarrheal diseases among under-five children identified in this study. Most of the identified determinants of diarrheal disease among under-five children in the study area are preventable. Thus, promoting households through the provision of continuous and modified health information on the importance of sanitation (proper domestic solid waste disposal, and latrine utilization), personal hygiene (hand-washing facility and proper handwashing practices at critical times), and vaccination against rotavirus which is fundamental to decrease the burden of diarrheal disease among under-five children.

\section{$449 \quad$ Recommendations}

District Health Office and Zonal Health Department should be encouraged the community to install a hand-washing facility nearby the latrine motivate the community to utilize the 
latrine properly and practiced hand-washing during a critical time and strengthen rotavirus vaccination for all under-five children

Health Extension Workers Should facilitate and give health information for parents/legal guardians on the importance of the availability of hand-washing facility near the latrine, personal hygiene, proper latrine utilization, hand-washing practice during a critical time, proper solid waste disposal practices, vaccination of rotavirus and homemade drinking water treatment practices. Local NGO Should work in collaboration with the District Health Office and other stakeholders on the construction of hand-washing facility nearby latrine, personal hygiene to protect the transmission of diarrhea disease from mother to child, on the initiation of handwashing practices during a critical time, and prepare places for proper solid waste disposal practices.

\section{Abbreviation}

AIDS, acquired immunodeficiency syndrome; AOR, adjusted odds ratio; CI, confidence interval; COR, crude odds ratio; EDHS, Ethiopian demographic and health survey; $\mathrm{HH}$, households; HO, health officer; PI, principal investigators; SD, standard deviation; SDG, sustainable development goal; SPSS, statistical package for social science; SSA, Sub Saharan Africa; U-5, under five years old children; UNICEF, United Nations Children's Fund

\section{Ethical Approval and Consent to participate}

471 Ethical clearance was obtained from the Ethical Review Board of Ambo University 472 College of Medicine and Health Sciences, with the Ref. No of PGC/18/2020.

473 Hierarchically all administrative bodies were communicated and permission was secured.

474 Written informed consent was obtained from the parent/legal guardian for study subjects 475 after explaining the objectives and procedures of the study and their right to participate or to withdraw at any time of the interview. The Research and Ethical Review Committee 
477 also approved its ethical issues as there was no procedure that affects the study subject and 478 the data is used only for research purposes. For this purpose, a one-page consent letter was 479 attached to the cover page of each questionnaire stating the general purpose of the study 480 and issues of confidentiality which were discussed by data collectors before proceeding to 481 the interview. Parent/legal guardian who was found that their children are sick during the study time they were consulted about the causes of the disease and refer her/him to a health facility nearby. Lastly, we confirm that this study was conducted in accordance with the Declaration of Helsinki.

\section{Consent for Publication}

Not Applicable

487

\section{Availability of data and materials}

The dataset used and analyzed throughout the present study accessible from the corresponding author based on reasonable request.

\section{Competing Interests}

491 The authors declare that no competing interests.

$492 \quad$ Funding

493 This research received no specific grant from any funding agency in the public, 494 commercial or not-for-profit sectors.

495

496

497

498 499

\section{Authors Contribution}

DM, MA, TG, ASH carried out all the conception and designing of the study, data collection, performed statistical analysis, wrote final report, reviewing and editing the final draft of the manuscript. All of the authors read and approved the final manuscript.

\section{Acknowledgments}


500 We would like to thank the study participants and all other peoples who had formally or

501 informally involved in the accomplishment of this research.

\section{Author information's'}

503 Dejene Mosisa, and Mecha Aboma (BSc, MPH) Lecturer at Department of Public Health 504 Collage of Medicine and Health Sciences, Ambo University, Oromia Ethiopia.

505 Email address: dejenem1976@gmail.com and abomamecha@gmail.com

506 Teka Girma and Abera Shibru (BSc, MPH) Assistance Professor at Department of Public

507 Health Collage of Medicine and Health Sciences, Ambo University, Oromia Ethiopia

508 Email address: teka_girma@yahoo.com and abera.shibru@yahoo.com

509 References

510 1. UNICEF/WHO. Why children are still dying and what can be done. New York:

$511 \quad$ UNICEF. 2009.

512 2. Peterson KM, Diedrich E, Lavigne J. Strategies for Combating Waterborne Diarrheal 513 Diseases in the Developing World. ES; 2008.

514 3. Chopra M, Binkin NJ, and Mason E, Wolfheim C. Integrated management of 515 childhood illness: what have we learned and how can it be improved? Archives of 516 disease in childhood. 2012; 97(4):350-4.

517 4. WHO. Progress on drinking water, sanitation and hygiene: 2017 update and SDG 518 baselines. Progress on drinking water, sanitation and hygiene: 2017 update and SDG $519 \quad$ baselines. 2017.

520 5. Azage M, Haile D. Factors associated with safe child feces disposal practices in 521 Ethiopia: evidence from demographic and health survey. Archives of Public Health. $522 \quad 2015 ; 73(1): 40$. 
6. UNICEF/WHO. Diarrhoea: why children are still dying and what can be done. Unicef Web site. 2016.

7. Belachew T, Jira C, Faris K, Mekete G, Asres T, Aragaw H. Diarrheal disease for the Ethiopian Health Center Team. Ethiopian Public health Training initiative. 2011:189.

8. Agency CS, ICF. Ethiopia Demographic and Health Survey 2016: Key Indicators Report. Addis Ababa, Ethiopia, and Rockville, Maryland, USA. CSA and ICF. 2016.

9. Walker CLF, Rudan I, Liu L, Nair H, Theodoratou E, Bhutta ZA, et al. Global burden of childhood pneumonia and diarrhoea. The Lancet. 2013; 381(9875):1405-16.

10. UNICEF. UNICEF Sri Lanka annual report 2005. Retrieved February. 2005; 29:2009.

11. Abbas J, Pandey DC, Verma A, Kumar V. Management of acute diarrhea in children: Is the treatment guidelines is really implemented. Int J Res Med Sci. 2018; 6:539-44.

12. Girma M, Gobena T, Medhin G, Gasana J, Roba KT. Determinants of childhood diarrhea in West Gojjam, Northwest Ethiopia: a case control study. Pan African Medical Journal. 2018; 30(1).

13. Brhanu H, Negese D, Gebrehiwot M. Determinants of acute diarrheal disease among under-five children in pawi hospital, Northwest Ethiopia. American Journal of Pediatrics. 2017; 2(2):29-36.

14. JGWHO. Jimma Geneti Woreda Health Office First Quarter work Report. Report. $2019 / 2020$.

15. Tarekegn M, Enquselassie F. A case control study on determinants of diarrheal morbidity among under-five children in Wolaita Soddo Town, Southern Ethiopia. Ethiopian Journal of Health Development. 2012; 26(2):78-85. 
16. Ayalew AM, Mekonnen WT, Abaya SW, Mekonnen ZA. Assessment of Diarrhea and its Associated Factors in Under-Five Children among Open Defecation and Open Defecation-Free Rural Settings of Dangla District, Northwest Ethiopia. Journal of environmental and public health. 2018.

17. WHO/UNICEF. Core questions on drinking water and sanitation for household surveys. 2006.

18. JGANRO. Jimma Geneti Agricaltural and Natural Resource Office Annual Work Report. Report. 2019.

19. Asfaha KF, Tesfamichael FA, Fisseha GK, Misgina KH, Weldu MG, Welehaweria NB, et al. Determinants of childhood diarrhea in Medebay Zana District, Northwest Tigray, and Ethiopia: a community based unmatched case-control study. BMC pediatrics. 2018; 18(1):120.

20. Megersa S, Benti T, Sahiledengle B. Prevalence of Diarrhea and Its Associated Factors among Under-Five Children in Open Defecation Free and Non-Open Defecation Free Households in Goba District Southeast Ethiopia: A Comparative Cross-Sectional Study. Clinics Mother Child Health. 2019; 16:324.

21. Ferede MM. Socio-demographic, environmental and behavioural risk factors of diarrhoea among under-five children in rural Ethiopia: further analysis of the 2016 Ethiopian demographic and health survey. BMC Pediatrics. 2020; 20(1):1-9.

22. Rohmawati N, Panza A, Lertmaharit S. Factors Associated with Diarrhea among Children Under Five Years of Age in Banten Province, Indonesia. Journal of Health Research. 2012; 26(1):31-4.

23. Edward A, Jung Y, Chhorvann C, Ghee AE, Chege J. Association of mother's handwashing practices and pediatric diarrhea: evidence from a multi-country study on community oriented interventions. BMC public health. 2019; 60(2):E93-e102. 
24. Degebasa MZ, Weldemichael DZ, Marama MT. Diarrheal status and associated factors in under five years old children in relation to implemented and unimplemented community-led total sanitation and hygiene in Yaya Gulele in 2017. Pediatric health, medicine and therapeutics. 2018; 9:109.

25. Workie GY, Akalu TY, Baraki AG. Environmental factors affecting childhood diarrheal disease among under-five children in Jamma district, South Wello zone, Northeast Ethiopia. BMC infectious diseases. 2019; 19(1):804.

26. Getachew B, Mengistie B, Mesfin F, Argaw R. Factors Associated with Acute Diarrhea among Children Aged 0-59 Months in Harar Town, Eastern Ethiopia. East African Journal of Health and Biomedical Sciences. 2018;2(1):26-35.

27. Reuben Mutama DM, Joseph Wakibia. Risk Factors Associated with Diarrhea Disease among Children Under-Five Years of Age in Kawangware Slum in Nairobi County, Kenya. Food and Public Health, 9(1): 1-6. 2019.

28. Beyene SG, Melku AT. Prevalence of Diarrhea and Associated Factors among Under Five Years Children in Harena Buluk Woreda Oromia Region, South East Ethiopia, 2018. Journal of Public Health International. 2018; 1(2):9.

29. Regassa W, Lemma S. Assessment of diarrheal disease prevalence and associated risk factors in children of 6-59 months old at Adama District rural Kebeles, eastern Ethiopia, and January/2015. Ethiopian journal of health sciences. 2016; 26(6):581-8.

30. Chiluba Musonda SS, Mwenya Kwangu, David Mulenga. Factors associated with diarrheal diseases in under-five children: a case control study at arthur davison children's hospital in Ndola, Zambia. Article. 2017.

31. Shine S, Muhamud S, Adanew S, Demelash A, Abate M. Prevalence and associated factors of diarrhea among under-five children in Debre Berhan town, Ethiopia 2018: a cross sectional study. BMC infectious diseases. 2020; 20(1):1-6. 
32. Shumetie G, Gedefaw M, Kebede A, Derso T. Exclusive breastfeeding and rotavirus vaccination are associated with decreased diarrheal morbidity among under-five children in Bahir Dar, northwest Ethiopia. Public health reviews. 2018; 39:28.

33. Tambe Betrand Ayuk, 2 Nyobe Emilienne, Carine NJA, 3 Ndzana Anne, Christine EaVJ, 1 Baleba, M Roger MGN, 1 Dapi, Leoni3 N. Prevalence of diarrhoea and associated risk factors among children under-fve years of age in Efoulan health district- Cameroon, sub-Saharan Africa. Journal of Health Research. 2018.

34. Randremanana RV, Razafindratsimandresy R, Andriatahina T, Randriamanantena A, Ravelomanana L, Randrianirina F, et al. Etiologies, risk factors and impact of severe diarrhea in the under-fives in Moramanga and Antananarivo, Madagascar. PloS one. 2016; 11(7):e0158862

35. O’Ryan M, Giaquinto C, Benninghoff B. Human rotavirus vaccine (Rotarix): focus on effectiveness and impact 6 years after first introduction in Africa. Expert Review of Vaccines. 2015; 14(8):1099-112.

36. Parashar UD, Tate JE. The control of diarrhea, the case of a rotavirus vaccine. salud pública de méxico. 2020; 62(1):1-5. 


\section{Figures}

\section{Conceptual Frame Work}

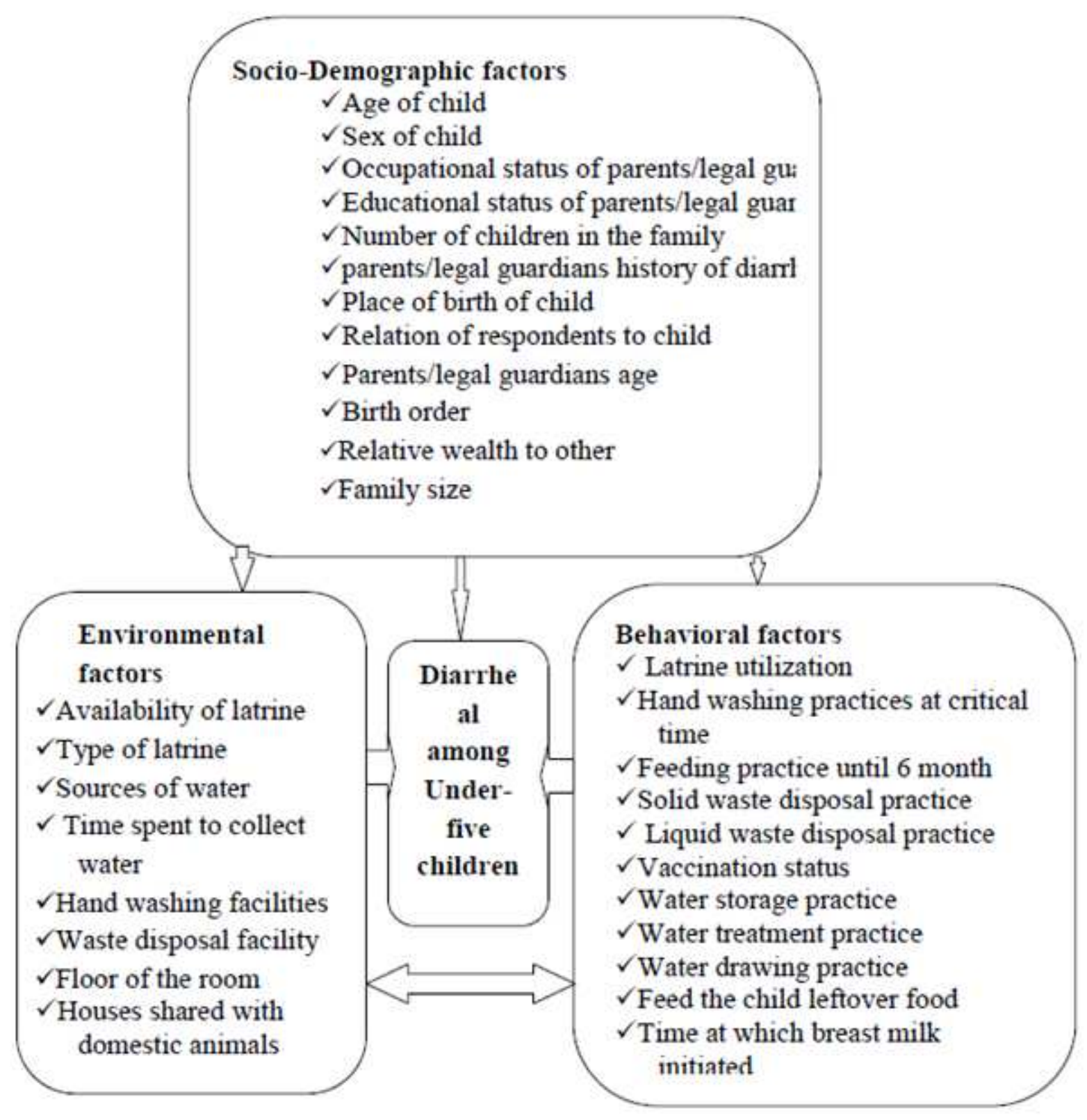

Figure 1

Conceptual framework on Determinants of Diarrheal Diseases among under-five Children in Jimma Geneti district, Oromia regional state, Western Ethiopia, May, $2020(15,16)$. 


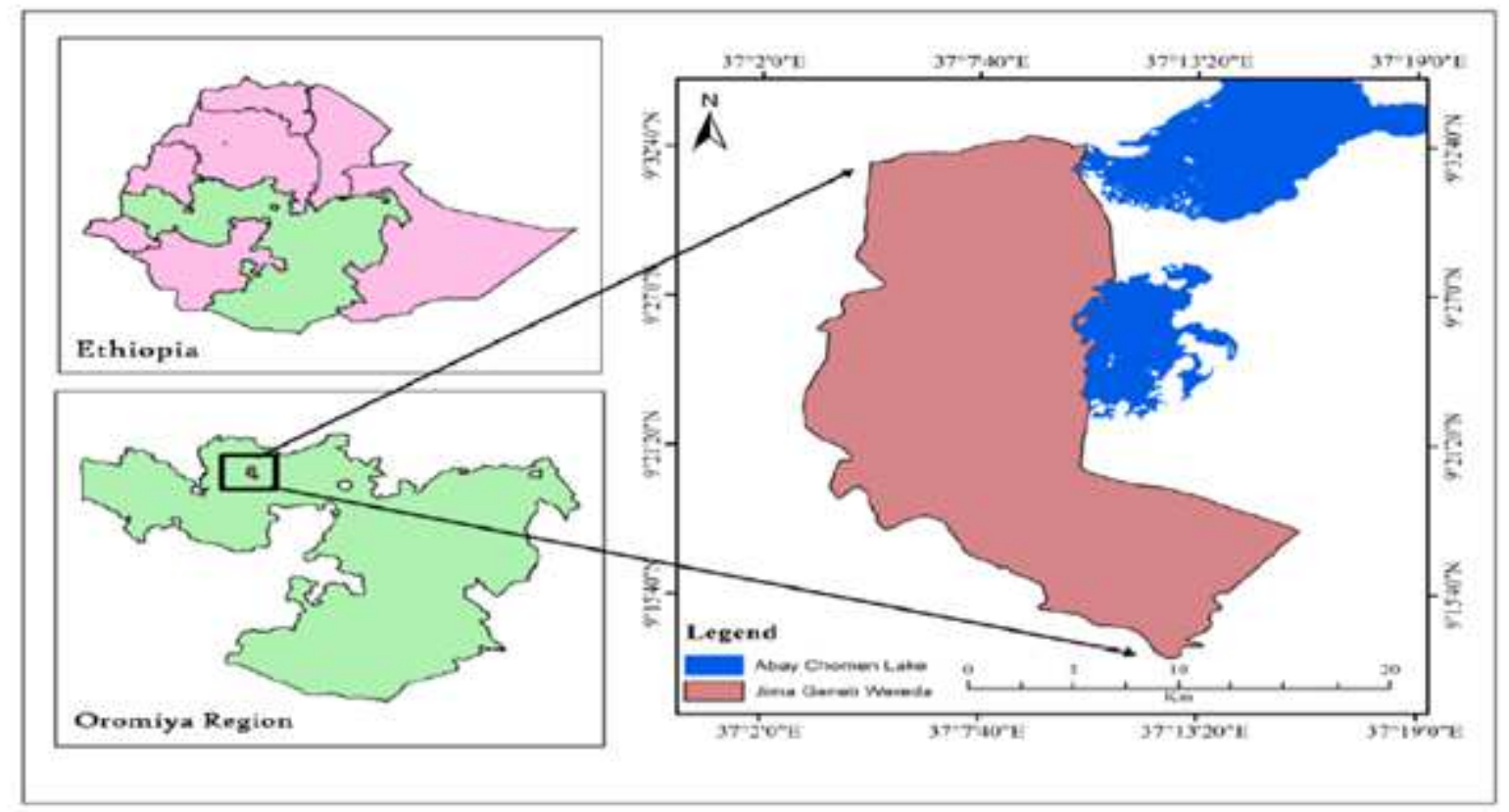

Figure 2

Location map of Jimma Geneti District: Nation, Region and, District, Oromia Regional state, Western Ethiopia, May, 2020 (14).

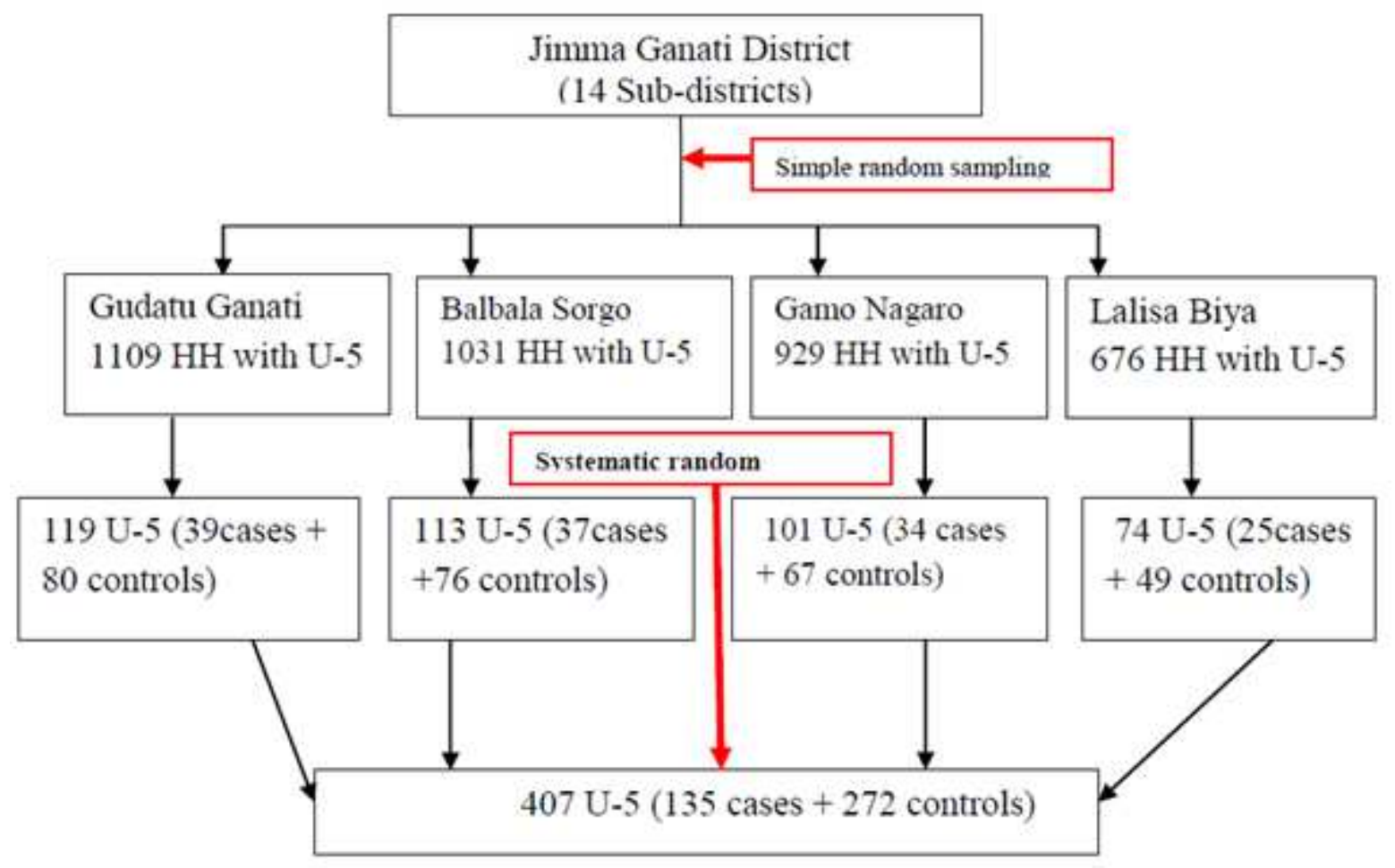

Figure 3 
Diagrammatic presentation of sampling technique of under-five children inJimma Geneti district, Oromia Regional state, Western Ethiopia, May, 2020. 